\title{
Early post-settlement mortality and the structure of coral assemblages
}

\author{
Lucie Penin $^{1,2,3, *}$, François Michonneau ${ }^{1,4}$, Andrew H. Baird ${ }^{3}$, Sean R. Connolly ${ }^{3,5}$ \\ Morgan S. Pratchett ${ }^{3}$, Mohsen Kayal ${ }^{1,2}$, Mehdi Adjeroud ${ }^{1,6}$ \\ ${ }^{1}$ UMR CNRS-EPHE-UPVD 5244 Biologie et Écologie Tropicale et Méditerranéenne, Université de Perpignan, \\ 66860 Perpignan Cedex, France \\ ${ }^{2}$ USR CNRS-EPHE 3278, CRIOBE, Université de Perpignan, BP 1013 Moorea, French Polynesia \\ ${ }^{3}$ ARC Centre of Excellence for Coral Reef Studies, James Cook University, Townsville, 4811 Queensland, Australia \\ ${ }^{4}$ Department of Biology, University of Florida, Gainesville, Florida 32611-7800, USA \\ ${ }^{5}$ School of Marine and Tropical Biology, James Cook University, Townsville, 4811 Queensland, Australia \\ ${ }^{6}$ Institut de Recherche pour le Développement, U 227 COREUS 2, CBETM, Université de Perpignan Via Domitia, \\ 66860 Perpignan Cedex, France
}

\begin{abstract}
Events occurring early in life history can have profound effects on the structure of populations and communities. In particular, susceptibility to predation is often highest early in life, and can greatly influence community structure. To better understand these events in reef-forming coral communities, we investigated how spatial variation in recruitment and early post-settlement predation influenced the spatial structure of a coral assemblage. Over a 5 yr period, we compared recruitment of corals and abundance of juveniles and adults at a combination of 3 locations and 3 depths in French Polynesia. We then measured mortality of recruits ( $<3$ mo old) and juveniles (about 1 to 4 yr old), and abundance of potential predators. Results demonstrate the crucial role of events occurring in the first weeks of the benthic stage. The abundance of scraping herbivorous parrotfishes explained substantial spatial variation in the mortality of recruits, but not juveniles, revealing a likely effect of incidental removal by grazing. Conversely, abundance of coral-feeding butterflyfishes explained substantial spatial variation in the mortality of juveniles. These findings underscore the importance of incidental mortality from grazing and specialized corallivory on coral populations. Moreover, these processes can play a key role in determining spatial patterns in coral assemblage structure.
\end{abstract}

KEY WORDS: Scleractinian corals · Recruitment · Predation · Grazing - Population structure · Coral reefs · Early life-history traits · Moorea · French Polynesia

Resale or republication not permitted without written consent of the publisher

\section{INTRODUCTION}

Population structure and dynamics are influenced by a complex set of interacting factors acting on different stages of organisms' life cycles. For marine organisms with a dispersive larval phase, the supply of larvae can vary in time and space, and stochastic settlement can exert a major influence on spatial and temporal heterogeneity among relatively site-attached adult assemblages (Caley et al. 1996). However, population structure also depends on processes occurring in the period following settlement. Early post-settlement mortality is usually very high (e.g. >90\% for marine invertebrates;
Gosselin \& Qian 1997), and is both spatially and taxonomically variable (Dalby \& Young 1992, Steele \& Forrester 2002). Thus early post-settlement mortality is likely to have substantial effects on spatial patterns in abundance and, where taxonomic variation in mortality is present, on assemblage structure (Gosselin \& Qian 1997, Steele \& Forrester 2002, Almany \& Webster 2006).

Predation is one of the most important biological processes affecting population dynamics and community structure, especially for species with juveniles or adults with small body sizes (Hixon 1991, Sundell 2006, Huang et al. 2008). Heavy predation on early life stages can play a major role in shaping assemblage structure 
for many organisms, including plants, fish and marine invertebrates (Ostfeld et al. 1997, Osman \& Whitlatch 2004, Almany \& Webster 2006). Scleractinian corals, in particular, are subject to high mortality early in life (e.g. Wilson \& Harrison 2005) which can be spatially, taxonomically and temporally variable (Babcock \& Mundy 1996, Baird \& Hughes 2000, Vermeij 2006). Predation is a possible cause of a large part of this mortality, even if direct evidence is scarce (Sammarco 1985, Christiansen et al. 2009). Therefore, corals are a good model for investigating effects of early stage mortality from predation on population and assemblage structure. Moreover, scleractinian corals are the key habitat-forming and foundation species of coral reef ecosystems (Jones et al. 2004); therefore, understanding the processes that maintain their populations is of crucial importance given increasing rates of coral mortality on reefs globally (Hughes et al. 2003).

The non-reproductive benthic phase of corals can be separated into a recruit stage, i.e. corals invisible to the naked eye on natural substrata, generally aged less than $1 \mathrm{yr}$, and a juvenile stage, observable in situ $(>1 \mathrm{~cm})$ and typically aged at least 1 yr (Banks \& Harriott 1996, Chiappone \& Sullivan 1996; Fig. 1). Most studies conducted on early post-settlement mortality of corals have focused either on recruits or juveniles, but rarely on both, probably because the techniques used to investigate each stage are different. Consequently, the relative importance of events occurring during each of these stages remains largely unknown. Recruit and juvenile stages are ecologically very different. Sizes vary by up to an order of magnitude between these stages (i.e. $1 \mathrm{~mm}$ at settlement versus $\sim 1 \mathrm{~cm}$ after $1 \mathrm{yr}$ ), and many processes such as mortality are sizedependent in corals (Brock 1979, Babcock 1985, Vermeij 2006). In addition, organisms interacting through competition or predation with recruits are likely to be different from those interacting with juveniles and/or to have differing severity in their effect on recruits versus juveniles (Christiansen et al. 2009).

In the present study, we examined the effects of recruitment and early post-settlement mortality in structuring adult coral assemblages by comparing the spatial distribution of recruits, juveniles and adults over a period of $5 \mathrm{yr}$. In addition, we assessed the extent to which spatial variation in grazing and corallivory from fishes and macroinvertebrates may explain spatial patterns in recruit and juvenile mortality. A growing body of studies highlights the capacity of some grazers to be detrimental to adult corals (Miller \& Hay 1996, GrottoliEverett \& Wellington 1997, Rotjan \& Lewis 2005, Rotjan \& Lewis 2008). However, the effect of corallivory on young corals has received little attention, despite the fact that removal of such corals is likely to be a major source of mortality, especially during the period immediately following settlement (Brock 1979, Sato 1985, Mumby 2009). Grazing is as an important ecological process on coral reefs, benefiting corals at the expense of their competitors for space, such as macroalgae (Hixon 1997, Mumby et al. 2007). However, the incidental removal of recruits by grazers is a major source of mortality for some sessile organisms (Denley \& Underwood 1979, Stoner 1990), and probably for coral recruits as well, given their small size and their interspersion with algae (Brock 1979, Sato 1985). To identify and quantify the effects of grazing and corallivory on early stage mortality, we estimated the mortality of recruits and juveniles in field conditions and then determined how much of the spatial variation in this mortality could be explained by variation in the abundances of potential predators. To extend previous studies which have focused either on recruits (e.g. Hughes et al. 1999) or juveniles (e.g. Ruiz-Zarate \& AriasGonzales 2004) exclusively, we explicitly compared mortality patterns during these 2 life stages.

Fig. 1. Coral life cycle, showing the specificities of the 3 benthic stages - recruit, juvenile and adult - and the parameters measured in the present study 


\section{MATERIALS AND METHODS}

Sampling stations. The present study was conducted at Moorea $\left(17^{\circ} 30^{\prime} \mathrm{S}, 149^{\circ} 50^{\prime} \mathrm{W}\right)$, in the Society Archipelago, French Polynesia. Sampling was undertaken on the outer reef slope in 3 water depths $(6,12$ and $18 \mathrm{~m}$ ) at each of 3 locations (Vaipahu, Tiahura and Haapiti), giving a total of 9 stations. Haapiti is located on the western shore and is directly exposed to the prevailing SW swell, while the other locations are situated on the northern shore and are more sheltered. Previous studies have demonstrated significant variation in coral recruitment (Adjeroud et al. 2007a) and juvenile and adult abundance (Penin et al. 2007) among these locations and depths. For a more detailed description of these sites, see Penin et al. (2007).

Recruitment patterns. To assess variation in settlement among stations, 20 unglazed terracotta tiles $(11 \times$ $11 \times 1 \mathrm{~cm}$ ) were deployed at each station following the direct attachment method (Mundy 2000). Each settlement plate was attached to the substratum using a small stainless steel base plate with a stainless steel bolt secured to the centre of the plate. The base plates were attached to the substratum with 2 plastic expansion plugs inserted through holes in the base plate into the substratum. The settlement plates were secured to the base plate with a stainless steel wing nut. The base plates were placed flush with the substratum and the heads of the plastic plugs provided a gap of about $1 \mathrm{~cm}$ between the settlement plate and the base plate, creating a gap habitat. Two consecutive sets of tiles were deployed on the base plates for 3 mo during the main recruitment period (September to December and December to March; Adjeroud et al. 2007a) every year for $5 \mathrm{yr}$ (2001-2002 to 2005-2006). The same base plates were kept in place during the whole experiment, so that the tiles were relocated at the exact same place. Once collected, all tiles were bleached and sundried, and then coral recruits present on each surface of the tiles (upperside, underside and edges) were counted and identified using a dissecting microscope. At this stage of development, the micro-architecture of the corallum is not sufficiently developed to allow high taxonomic resolution; therefore, recruits were categorized to each of the 3 families that together constitute the overwhelming majority of coral cover in this reef system (Acroporidae, Pocilloporidae and Poritidae), following Babcock et al. (2003). In Moorea, the family Acroporidae only encompasses 3 genera (Acropora, Montipora and the uncommon Astreopora), whereas Pocilloporidae and Poritidae are each represented by only 1 genus (Pocillopora and Porites, respectively). All Acropora, Montipora, Pocillopora and Porites species for which reproductive data exist are broadcast spawners on the outer slopes of Moorea.
Comparison of recruitment on natural and artificial substrata showed that natural spatial variation of recruit abundance among stations was conserved on tiles, and relative abundance of the 3 families studied (Acroporidae, Pocilloporidae and Poritidae) was similar on tiles and on natural substrata (Appendix 1). As a consequence, the use of tiles does not introduce a bias in the comparison of spatial patterns of recruits, juveniles and adults among the study stations.

Juvenile and adult abundance patterns. Juveniles were defined as colonies with maximum diameters between 1 and $5 \mathrm{~cm}$, whereas colonies $>5 \mathrm{~cm}$ maximum diameter were regarded as adults (e.g. Miller et al. 2000). For each of the 6 major genera (Pocillopora, Acropora, Porites, Pavona, Montastrea and Montipora), colonies $<5 \mathrm{~cm}$ maximum diameter are most likely non-reproductive (Harrison \& Wallace 1990). Juvenile and adult corals were sampled on natural reef substrates along 3 replicate permanent $10 \times 1 \mathrm{~m}$ belt transects at each station, once a year for $5 \mathrm{yr}$ (2003 to 2007). All the colonies at least partially enclosed in the belt transects were counted and identified to the genus level. Because juveniles are at least 1 yr old, sampling was initiated $1 \mathrm{yr}$ after the first recruitment sampling. Transects were parallel to the depth contour and separated by $>2 \mathrm{~m}$. Spearman non-parametric correlations were used to determine the relationships among recruit, juvenile and adult abundance variation among stations. Because juvenile and adult assemblages are the result of several years of recruitment, data were pooled among years for the main analysis, the objective being to determine if spatial variation in juvenile and adult abundance was correlated with spatial variations in recruitment patterns over time. Nevertheless, year-by-year analyses were also carried out to ensure that results of the pooled analysis were consistent with those for individual years.

Effect of predation on recruit mortality. A manipulative experiment was used to determine the predation-induced mortality rate at the 9 study stations. Four PVC racks containing 6 tiles each were deployed at each station for 3 mo during the main recruitment period (December to March). PVC racks $(53 \times 37 \mathrm{~cm})$ were attached flush with the substratum with polyamide strings. On each PVC rack, 6 unglazed terracotta tiles were attached horizontally using a stainless steel bolt. To maintain a gap between the tiles and the PVC rack, drops of silicone glue of about $1 \mathrm{~cm}$ high were used to act as shock absorbers. After 3 mo, half of the tiles from each of the 36 experimental racks were turned over. Initially, the underside of the tiles was protected from predation by macropredators, as the gap between the bottom of the tile and the PVC rack did not exceed $1 \mathrm{~cm}$. After being turned upside down, the underside of the tiles was exposed to predators. 
After 7 more days, all tiles were brought back to the laboratory and bleached for further examination under a dissecting microscope. The number of intact and broken recruit skeletons was recorded on each tile. The effect of overturning tiles on the abundance of intact recruits was assessed using a 3-way ANOVA (site $x$ depth $\times$ treatment). To ensure residual variation was approximately Gaussian and homoscedastic, data were square root transformed prior to analysis. Mortality caused by predation was calculated for each rack by subtracting the number of intact recruits on overturned tiles from the number of intact recruits on control (not flipped) tiles. As a consequence, only the predation inducing partial or total skeleton damage is included in what is hereinafter called predationinduced mortality. Although some natural variation in recruit densities among tiles was undoubtedly present (Baird \& Hughes 1997), this was not expected to create differences in initial abundance between the control and manipulated batches (each containing 12 tiles per station), since tiles for the 2 treatments were interspersed with one another on the same racks. Nevertheless, given low enough mortality and variation in initial abundance among tiles, it was possible for exposed tiles to end up with more recruits than protected ones. However, this only happened at 1 of our 9 stations (T18): we thus set mortality for this station to zero.

The abundance of potential predators was quantified at all 9 stations for comparison with recruit mortality. Invertebrate predators (Acanthaster planci, grazing urchins and carnivorous mollusks) were counted on each of the 3 permanent belt transects present at every station. These censuses were conducted once during the day and once at night, except at Haapiti, where censuses were conducted only during the day for logistical and safety reasons. Due to the very low abundance of potential invertebrate predators on the outer reef slopes of Moorea during the present study (in total, only 4 and 5 grazing urchins were counted during day and night censuses, respectively, and 3 A. planci during night censuses), only predation by fish was considered. Most specialized corallivore fish in Moorea are Chaetodontidae (Harmelin-Vivien \& Bouchon-Navaro 1983), but some select species from several other families including the Balistidae, Labridae and Monacanthidae also feed on corals (Cole et al. 2008). In addition, other families of fishes that are predominantly herbivorous (e.g. Scaridae) may cause incidental mortality of young corals while scraping algae from carbonate substrates (Hixon 1997, Cole et al. 2008).

Fishes of the families Chaetodontidae, Balistidae, Monacanthidae, Labridae, Acanthuridae and Scaridae were counted and identified in belt transects of $100 \mathrm{~m}^{2}$ $(2 \times 50 \mathrm{~m})$. At each station, counting was repeated 3 times on 2 consecutive days during the period when coral recruit mortality was measured (i.e. 10 to 15 March 2005). As all the targeted species are diurnal, counting was performed after 10:00 h and before 16:00 h.

Linear mixed effect models were used to assess the relationship between recruit mortality and abundance of the families Acanthuridae, Balistidae, Chaetodontidae, Monacanthidae, Labridae and Scaridae, using station as a random effect. Box-Cox transformations of the data were used to ensure an approximately Gaussian distribution of the residuals. Each linear mixed effect model was then tested against the corresponding model omitting the random effect using a likelihood ratio test. When there was no significant difference between the 2 models, the simpler model (i.e. the model omitting the random effect) was used for statistical inference.

Juvenile mortality patterns. Juvenile mortality was evaluated at each station for 2 different periods of time, and mortality patterns were then compared with potential predator abundance. To characterize juvenile mortality, 10 to $16 \times 1 \mathrm{~m}^{2}$ permanent quadrats were randomly selected along each of the 3 permanent belt transects at each station. All the juvenile colonies were counted, identified to genus and mapped. The number of quadrats varied as a function of juvenile abundance in order to sample at least 50 juveniles per station. Quadrats were re-surveyed after 4 and 14 mo (in August 2004 and June 2005, respectively) to determine juvenile survivorship. Spatial variation of juvenile mortality was assessed using 2-way ANOVA (Location $\times$ Depth) on percent mortality after 4 and 14 mo. To ensure residual variation was approximately Gaussian and homoscedastic, data were arcsine transformed prior to analysis.

Juvenile coral mortality patterns were then compared with the patterns of fish abundance of the families Acanthuridae, Balistidae, Chaetodontidae, Labridae, Monacanthidae and Scaridae. As described above, linear mixed effects models using station as a random effect and the corresponding models omitting the random effect were used to assess the correlation between abundance of the different fish families and juvenile coral mortality.

\section{RESULTS}

\section{Relationships among recruits, juveniles and adults}

Three main families, Pocilloporidae (genus Pocillopora), Acroporidae (genera Acropora, Montipora and Astreopora) and Poritidae (genus Porites), accounted for more than $70 \%$ of corals recorded in each life history stage (Fig. 2), and so limited consideration was given to other taxa. Relative contributions of families in 
the adult assemblage were very similar to those of the juvenile assemblage (respectively, Pocilloporidae: 30.7 and 30.3\%, Acroporidae: 25.2 and 26.9\%, Poritidae: 14.1 and $13.0 \%$ ), but the recruit assemblage differed from juvenile and adult assemblages, with a much higher proportion of Pocilloporidae (68.0\%) and a lower proportion of Acroporidae (11.7\%).

For the total assemblage (all taxa pooled), mean abundance of juveniles over 5 yr was positively correlated with adult abundance (Table 1). However, there was no correlation between mean abundances of recruits and adults, nor was there a correlation between mean abundances of recruits and juveniles. Year-by-year correlations carried out on all taxa pooled support these results (Table S1 in the online Supplement available at www.int-res.com/articles/ suppl/m408p055_supp.pdf). Specifically, juvenile-adult correlations were positive in all 15 year-by-year comparisons, and about half were individually statistically significant. In contrast, for the comparisons involving recruits, the direction of correlation varied among years, and none of the year-by-year comparisons were statistically significant. Variations in the abundance of recruits for the $5 \mathrm{yr}$ of the study are presented in Fig. S1 in the Supplement, and recruitment patterns across the 9 study stations are presented in Adjeroud et al. (2007a).

Relationships among recruits, juveniles and adults varied among taxa (Tables 1 \& S1). For Pocilloporidae, there were no significant correlations among recruit, juvenile and adult abundance: neither pooled nor year-by-year correlations were significant. For Acroporidae, mean juvenile abundance was positively and significantly correlated with mean recruit abundance over $5 \mathrm{yr}$, and juvenile abundance of individual years was generally correlated with recruit abundance over 5 yr. Juvenile abundance was also positively and sig-

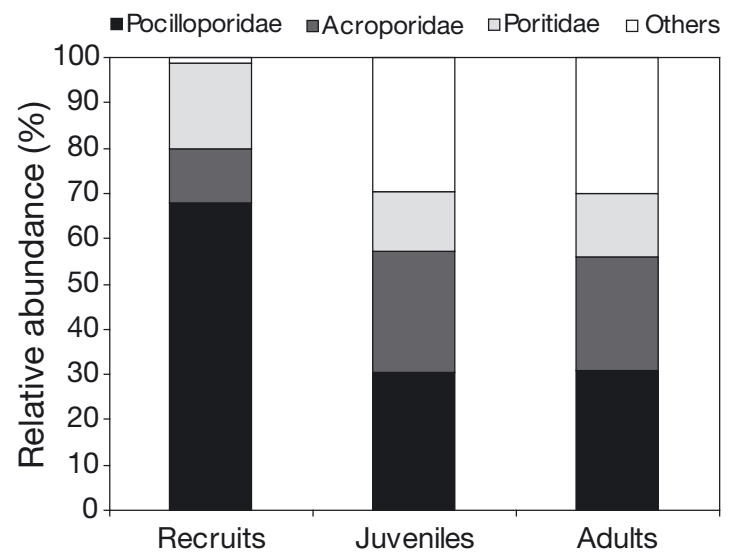

Fig. 2. Proportion of Pocilloporidae, Acroporidae, Poritidae and other families in recruit, juvenile and adult coral assemblages around Moorea (all stations pooled)
Table 1. Non-parametric correlations among abundance at the 9 sampling stations of recruits, juveniles and adults for all taxa pooled, Pocilloporidae, Acroporidae and Poritidae. All years pooled. $\rho$ : Spearman non-parametric correlation coefficient; ns: not significant

\begin{tabular}{|lcccc|}
\hline \multicolumn{2}{c}{ Recruits } & \multicolumn{2}{c|}{ Juveniles } \\
& $\rho$ & $\mathrm{p}$ & $\rho$ & $\mathrm{p}$ \\
\hline All taxa pooled & & & & \\
$\begin{array}{l}\text { Adults } \\
\text { Juveniles }\end{array}$ & 0.167 & $\mathrm{~ns}$ & 0.690 & $<0.0001$ \\
Pocilloporidae & 0.233 & $\mathrm{~ns}$ & & \\
$\begin{array}{l}\text { Adults } \\
\text { Juveniles }\end{array}$ & 0.233 & $\mathrm{~ns}$ & -0.016 & $\mathrm{~ns}$ \\
$\begin{array}{l}\text { Acroporidae } \\
\text { Adults }\end{array}$ & -0.433 & $\mathrm{~ns}$ & & \\
Juveniles & 0.567 & $\mathrm{~ns}$ & 0.567 & 0.0002 \\
Poritidae & 0.833 & 0.0184 & & \\
Adults & & & & \\
Juveniles & 0.770 & 0.0294 & 0.458 & 0.0197 \\
& 0.748 & 0.0034 & & \\
\hline
\end{tabular}

nificantly correlated with adult abundance over 5 yr, and each of the correlation coefficients for the corresponding year-by-year comparisons were positive as well. Correlations between juvenile and adult abundance were also ubiquitously positive. Conversely, recruit abundance was not significantly correlated with adult abundance, although it is worth noting that, as with the other Acroporidae comparisons, all of the year-by-year correlation coefficients were positive. For Poritidae, all of the pooled correlations involving recruits, adults and juveniles were positive and statistically significant, and all of the correlation coefficients for the year-by-year comparisons were positive as well.

\section{Effect of predation on recruit mortality}

Intact recruits were more abundant on control tiles (10.92 recruits tile ${ }^{-1}$ ) than on overturned tiles (8.39 recruits tile ${ }^{-1}$; ANOVA, $F_{1}=14.068, \mathrm{p}=0.0002$ ), and varied among locations and depths $\left(F_{2}=9.362\right.$, p < 0.0001 and $F_{2}=23.785, \mathrm{p}<0.0001$ ), with no significant interaction.

Recruit mortality $1 \mathrm{wk}$ after exposing the underside of tiles to potential predators and grazers varied from $0 \%$ at Stn T18 to $69.2 \%$ at Stn T6, with a mean of $23.7 \%$ (Fig. 3). There was no evidence for a random effect of station (ANOVA, p > 0.05). However, recruit mortality was positively and significantly related to the local abundance of Scaridae (linear model, $\mathrm{R}=0.804$, $\mathrm{p}=0.0157$ ) (Fig. 4), but not Acanthuridae, Balistidae, Chaetodontidae, Labridae or Monacanthidae (all p > 0.05). 

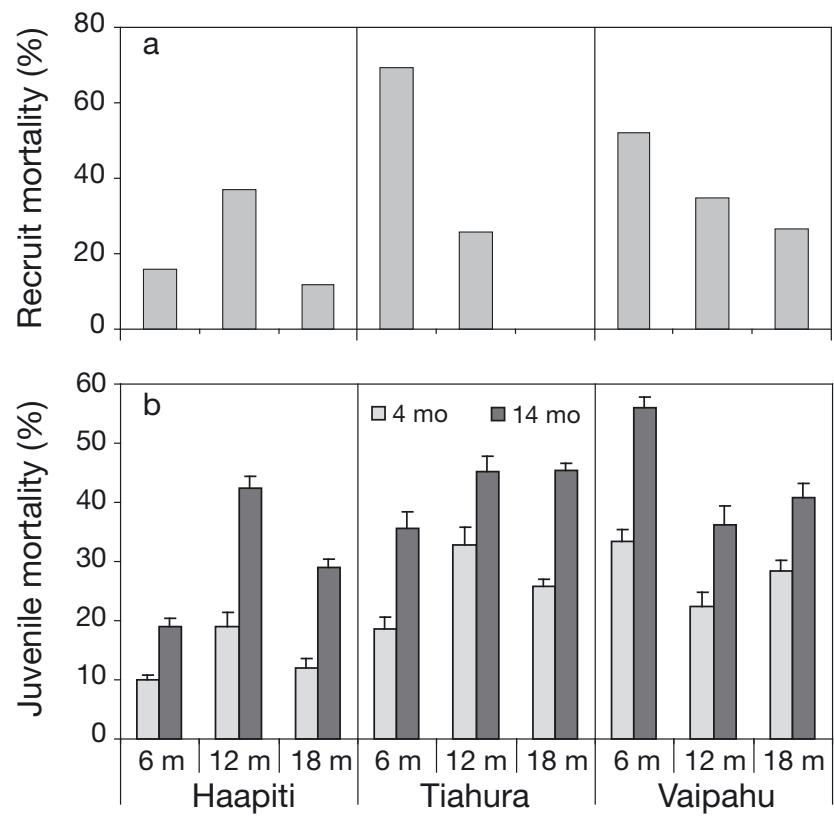

Fig. 3. Early stage mortality. (a) Predation-induced mortality of recruits during $1 \mathrm{wk}$ at the 9 stations, calculated as the difference between abundance of intact recruits on control and overturned tiles. At $18 \mathrm{~m}$ at Tiahura (Stn T18), abundance of recruits was slightly higher on overturned tiles than on control tiles; mortality was thus set to 0 . (b) Mean juvenile mortality over 4 and 14 mo at the 9 stations. Error bars: +SE

\section{Mortality patterns of juvenile corals}

Mean $( \pm \mathrm{SD}$ ) juvenile mortality was $23.6 \pm 8.2 \%$ after 4 mo and $39.4 \pm 10.6 \%$ after 14 mo (all stations and genera pooled). Mortality rates varied significantly among locations and depths (ANOVA, 4 mo: Location: $F_{2}=6.452, \mathrm{p}=0.0027 ; 14$ mo: Location $\times$ Depth: $F_{4}=$ 28.48, $\mathrm{p}=0.0288$; Location: $F_{2}=6.000, \mathrm{p}=0.037$ ) (Fig. 2). However, patterns of spatial variation were very similar after 4 and 14 mo (Fig. 3).
Juvenile mortality was positively and significantly related to local abundance of Chaetodontidae (linear model, 4 mo: $\mathrm{R}=0.458, \mathrm{p}=0.0270 ; 14$ mo: $\mathrm{R}=0.464$, $\mathrm{p}=0.0464$ ) (Fig. 4), but not Acanthuridae, Balistidae, Labridae, Monacanthidae or Scaridae (all p > 0.05).

\section{DISCUSSION}

The spatial patterns and taxonomic composition of adult coral populations at Moorea did not reflect spatial and taxonomic variation in recruitment rates, as measured by the relative abundance of different taxa settling to terracotta tiles. This suggests that differences in mortality during the early post-settlement phase among the major coral taxa, among locations and among depths can be important in determining the final taxonomic composition and spatial distribution of coral assemblages. Discrepancies among families in maintenance processes are probably linked with specific life history traits. Pocilloporidae appeared to settle in disproportionately higher abundance compared to other families, but then probably experienced higher rates of early post-settlement mortality. Pocillopora is generally described as an opportunistic genus, capable of high recruitment but presenting high turnover and mortality (Tomascik et al. 1996, Adjeroud et al. 2007b). Contrary to other families, the relative abundance of juvenile and adult Poritidae was positively correlated with local densities of recruits among stations and throughout the 5 yr study. For this family, higher abundance of recruits appeared to translate directly to higher abundance of juveniles and adults. Poritidae are characterized by a high resistance to harsh conditions, such as high turbidity and variable salinity (Wittenberg \& Hunte 1992), and natural disturbances, in particular coral bleaching (Baird \& Marshall 2002), which is a recurrent event on the reefs of
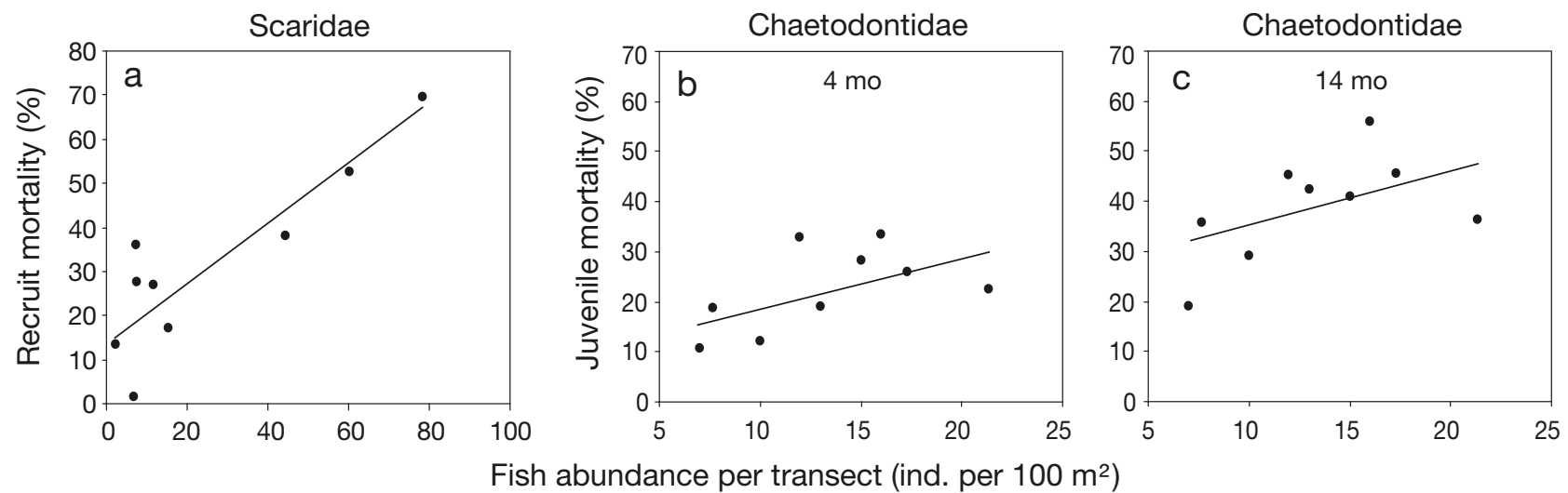

Fig. 4. Influence of fish predation on early stage mortality. (a) Predation-induced mortality of recruits during 1 wk versus abundance of scarids at the 9 study stations. (b) Mean juvenile mortality over 4 mo versus abundance of Chaetodontidae. (c) Mean juvenile mortality over 14 mo versus abundance of Chaetodontidae 


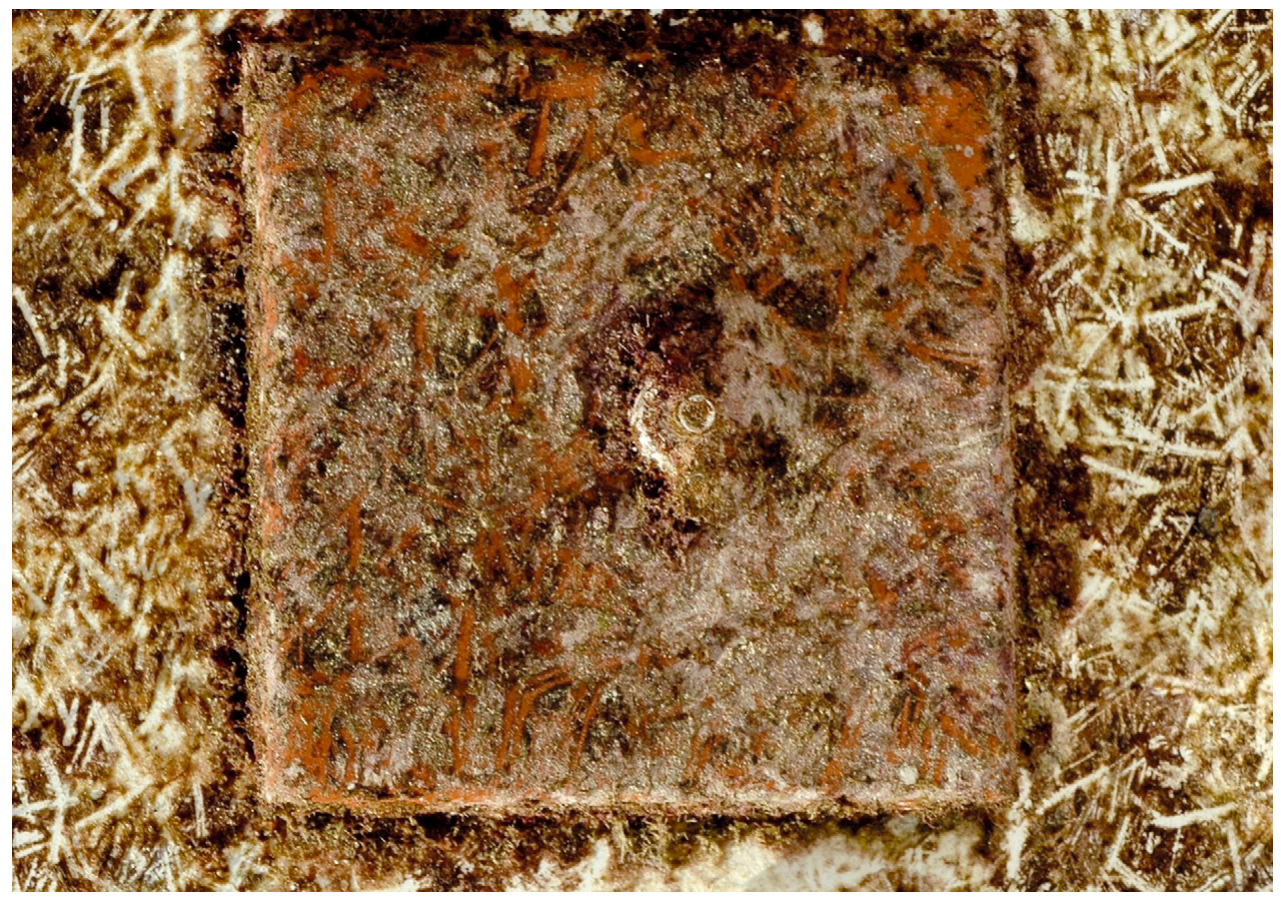

Fig. 5. Tile immersed for 3 mo, showing typical Scaridae bite marks

Moorea (Adjeroud et al. 2009). This higher resistance may be responsible for lower post-settlement mortality and the strong relationship between recruit, juvenile and adult abundance. For Acroporidae, spatial distribution of juveniles was largely dependent upon previous recruitment events and adult distribution was also contingent on juvenile patterns, but we failed to detect any significant relationship between recruit and adult patterns. Thus, for this family, it is difficult to discriminate the relative importance of recruitment and early stage mortality. It is possible, particularly for the abundant genus Acropora, that some of the adults originate as asexually generated fragments (Smith \& Hughes 1999), which could explain the absence of a relationship between adult and recruit distributions.

In the present study, local densities of Scaridae explained $65 \%$ of the spatial variation in recruit mortality associated with exposing settlement substrates to potential predators and grazers, suggesting that incidental mortality by grazing parrotfishes was responsible for a substantial proportion of the high predation induced recruit mortality ( $27 \%$ in $7 \mathrm{~d}$ ). Scaridae, while highly diverse in their ecology, are the primary family of fishes responsible for recurrent grazing of reef substrates (Bellwood et al. 2004, Mumby et al. 2007). At our stations, this family was mainly represented by Chlorurus sordidus (42.5\%), Scarus psittacus (41.5\%), S. oviceps (5.7\%), S. globiceps $(4.8 \%)$ and S. altipinnis $(2.1 \%)$, the other species representing less than $1 \%$ of the scarid assemblage. These Scaridae consume algae by grazing the substratum, removing both calcareous material and algal organic matter. Although some Scaridae are able to detect and avoid small corals (3 mm; Birkeland 1977), it is likely that many smaller recruits are included in the substantial amount of coral material that they ingest (Bellwood et al. 2004). The high abundance of Scaridae in Moorea (Galzin 1987), their method of grazing and the numerous scrape marks typical of Scaridae grazing activity on settlement tiles (Fig. 5) support the hypothesis of a causal relationship between Scaridae abundance and recruit mortality. Other possible sources of recruit mortality include changes in environmental conditions due to the overturning of the tiles. In particular, light levels and sedimentation will be higher on overturned tiles, although in these high energy stations, sediment is unlikely to accumulate, nor are light levels likely to stress the corals and damage their skeletons.

Spatial patterns of juveniles were highly correlated with those of adults, suggesting juvenile mortality was not sufficiently variable in space and/or intensity to influence spatial pattern in adult abundances. Scarid abundance explained significant spatial variation in recruit mortality but not juvenile mortality, suggesting that juveniles were less susceptible to incidental mortality due to grazers than recruits (Christiansen et al. 2009). However, Chaetodontidae abundance explained a significant part of juvenile mortality, suggesting an effect of specialized corallivory, as observed for adult corals. Chaetodontidae are the most abun- 
dant and specialized coral feeders, and corals represent an important part (between 60 and $100 \%$ ) of the diet of abundant chaetodontid species in Moorea like Chaetodon pelewensis, C. reticulatus and C. ornatissimus (Harmelin-Vivien \& Bouchon-Navaro 1983). While butterflyfishes rarely kill adult corals (Rotjan \& Lewis 2008), polyp feeding may be sufficient to kill small corals. Moreover, differential feeding by butterflyfishes can influence the outcomes of interspecific competition and patterns of abundance for major prey species (Neudecker 1979). Importantly, most butterflyfishes target either Acroporidae or Pocilloporidae (Pratchett 2005), having a disproportionate impact on these corals. This highlights the need for further examination of the role of corallivory on different coral life cycle stages.

Mortality rates of juvenile corals in Moorea (10 to $33 \%$ over 4 mo and 19 to $56 \%$ over 14 mo, depending on the station) are quite similar to those observed elsewhere: in Florida, annual mortality in Biscayne Bay ranged from 22 to $49 \%$ (Miller et al. 2000); in Bonaire, mortality rates were $32 \%$ over 6 mo (Bak \& Engel 1979); on the Great Barrier Reef, annual mortality of juveniles was $36 \%$ (Connell 1973). Potential sources of juvenile mortality are numerous and include competition with other benthic organisms, and sedimentation (Miller \& Hay 1996, Grottoli-Everett \& Wellington 1997, Rotjan \& Lewis 2005, Rotjan \& Lewis 2008). While we cannot eliminate these factors as sources of mortality in the present study, the correlation with predator abundance suggests predation may have an important and underappreciated role in population dynamics of susceptible coral species.

In conclusion, we show that there are marked differences in the proportional representation of major coral families at different life history stages in Moorea. Specifically, Pocilloporidae are overrepresented in assemblages of coral recruits compared to those of juveniles and adults. In addition, spatial variation in recruit abundance was a poor predictor of spatial variation in abundance for Acroporidae and Pocilloporidae, whereas a strong positive correlation was found for Poritidae. Moreover, our analyses indicate that spatial variation in predation is likely to play a significant role in the distribution of adult corals. Specifically, incidental predation by Scaridae explained substantial spatial variation in mortality of recruits, whereas corallivory by Chaetodontidae explained a large proportion of the spatial variation in juvenile coral mortality. These findings support an emerging consensus that predation on early life stages (including incidental predation) is a major cause of population regulation and the structure of assemblages in marine organisms (Gosselin \& Qian 1997, Almany \& Webster 2006). Most research on the effects of fishes on coral reefs has emphasized the indi- rect benefits of grazing, e.g. reducing algal abundance and facilitating coral recruitment and growth (McCook et al. 2001, Bellwood et al. 2004, Mumby 2009). We show that there are also important direct effects, with the feeding activities of different fish influencing assemblage structure of corals by causing mortality on different stages in the coral life cycle.

Acknowledgements. We thank Y. Chancerelle, T. Lison de Loma, J. Algret, P. Ung, E. Rouanet and numerous students for their help with fieldwork. This research was conducted at USR CNRS-EPHE 3278 CRIOBE, and was supported by grants from the French Ministère de l'Education Nationale, de la Recherche et de la Technologie, from the Plan Pluri Formation EPHE and from the French Ministère de l'Outre-Mer.

\section{LITERATURE CITED}

Adjeroud M, Penin L, Carroll A (2007a) Spatio-temporal heterogeneity in coral recruitment around Moorea, French Polynesia: implications for population maintenance. J Exp Mar Biol Ecol 341:204-218

- Adjeroud M, Pratchett M, Kospartov M, Lejeusne C, Penin L (2007b) Small-scale variability in the size structure of scleractinian corals around Moorea, French Polynesia: patterns across depths and locations. Hydrobiologia 589: $117-126$

Adjeroud M, Michonneau F, Edmunds PJ, Chancerelle Y and others (2009) Recurrent disturbances, recovery trajectories, and resilience of coral assemblages on a South Central Pacific reef. Coral Reefs 28:775-780

> Almany G, Webster M (2006) The predation gauntlet: early post-settlement mortality in reef fishes. Coral Reefs 25: $19-22$

Babcock RC (1985) Growth and mortality in juvenile corals (Goniastrea, Platygyra and Acropora): the first year. Proc 5th Int Coral Reef Congr 4:355-360

> Babcock RC, Mundy C (1996) Coral recruitment: consequences of settlement choice for early growth and survivorship in two scleractinians. J Exp Mar Biol Ecol 206: 179-201

Babcock RC, Baird AH, Piromvaragorn S, Thomson DP, Wills BL (2003) Identification of scleractinian coral recruits from Indo-Pacific Reefs. Zool Stud 42:211-226

Baird AH, Hughes TP (1997) Spatial variation in coral recruitment around Lizard Island, Australia. Proc 8th Int Coral Reef Symp 2:1207-1210

Baird AH, Hughes TP (2000) Competitive dominance by tabular corals: an experimental analysis of recruitment and survival of understorey assemblages. J Exp Mar Biol Ecol 251:117-132

Baird AH, Marshall PA (2002) Mortality, growth and reproduction in scleractinian corals following bleaching on the Great Barrier Reef. Mar Ecol Prog Ser 237:133-141

Bak RPM, Engel MS (1979) Distribution, abundance and survival of juvenile hermatypic corals (Scleractinia) and the importance of life history strategies in the parent coral community. Mar Biol 54:341-352

Banks SA, Harriott VJ (1996) Patterns of coral recruitment at the Gneering Shoals, southeast Queensland, Australia. Coral Reefs 15:225-230

> Bellwood DR, Hughes TP, Folke C, Nyström M (2004) Confronting the coral reef crisis. Nature 429:827-833

Birkeland CE (1977) The importance of rate of biomass accumulation in early successional stages of benthic communi- 
ties to the survival of coral recruits. Proc 3rd Int Coral Reef Symp 1:15-21

Brock R (1979) An experimental study on the effects of grazing by parrotfishes and role of refuges in benthic community structure. Mar Biol 51:381-388

Caley MJ, Carr MH, Hixon MA, Hughes TP, Jones GP, Menge BA (1996) Recruitment and the local dynamics of open marine populations. Annu Rev Ecol Syst 27:477-500

> Chancerelle Y (2000) Méthodes d'estimation des surfaces développées de coraux scléractiniaires à l'échelle d'une colonie ou d'un peuplement. Oceanol Acta 23:211-219

Chiappone M, Sullivan K (1996) Distribution, abundance and species composition of juvenile scleractinian corals in the Florida reef tract. Bull Mar Sci 58:555-569

Christiansen N, Ward S, Harii S, Tibbetts I (2009) Grazing by a small fish affects the early stages of a post-settlement stony coral. Coral Reefs 28:47-51

Cole AJ, Pratchett MS, Jones GP (2008) Diversity and functional importance of coral-feeding fishes on tropical coral reefs. Fish Fish 9:286-307

Connell JH (1973) Population ecology of reef-building corals. In: Jones OA, Endean R (eds) Biology and geology of coral reefs, Vol II. Academic Press, New York, p 205-245

> Dalby JE Jr, Young CM (1992) Role of early post-settlement mortality in setting the upper limit of ascidians in Florida epifaunal communities. Mar Ecol Prog Ser 80:221-228

> Denley EJ, Underwood AJ (1979) Experiments on factors influencing settlement, survival, and growth of two species of barnacles in New South Wales. J Exp Mar Biol Ecol 36:269-293

Galzin R (1987) Structure of fish communities of French Polynesian coral reefs. II. Temporal scales. Mar Ecol Prog Ser 41:137-145

Gosselin LA, Qian PY (1997) Juvenile mortality in benthic marine invertebrates. Mar Ecol Prog Ser 146:265-282

Grottoli-Everett AG, Wellington GM (1997) Fish predation on the scleractinian coral Madracis mirabilis controls its depth distribution in the Florida Keys, USA. Mar Ecol Prog Ser 160:291-293

Harmelin-Vivien ML, Bouchon-Navaro Y (1983) Feeding diets and significance of coral feeding among Chaetodontid fishes in Moorea (French Polynesia). Coral Reefs 2:119-127

Harrison PL, Wallace CC (1990) Reproduction, dispersal and recruitment of scleractinian corals. In: Dubinsky Z (ed) Coral reefs, Vol 25. Elsevier, Amsterdam, p 133-207

Hixon MA (1991) Predation as a process structuring coral reef fish communities. In: Sale PJ (ed) The ecology of fishes on coral reefs. Academic Press, San Diego, CA, p 475-509

Hixon MA (1997) Effects of reef fishes on corals and algae. In: Birkeland C (ed) Life and death of coral reefs. Chapman \& Hall, New York, p 230-248

> Huang SC, Norval G, Tso IM (2008) Predation by an exotic lizard, Anolis sagrei, alters the ant community structure in betelnut palm plantations in southern Taiwan. Ecol Entomol 33:569-576

> Hughes TP, Baird AH, Dinsdale EA, Moltschaniwskyj NA, Pratchett MS, Tanner JE, Willis BL (1999) Patterns of recruitment and abundance of corals along the Great Barrier Reef. Nature 397:59-63

Hughes TP, Baird AH, Bellwood DR, Card M and others (2003) Climate change, human impacts, and the resilience of coral reefs. Science 301:929-933

> Jones GP, McCormick MI, Srinivasan M, Eagle JV (2004) Coral decline threatens fish biodiversity in marine reserves. Proc Natl Acad Sci USA 101:8251-8253

McCook LJ, Jompa J, Diaz-Pulido G (2001) Competition between corals and algae on coral reefs: a review of evidence and mechanisms. Coral Reefs 19:400-417
Miller MW, Hay ME (1996) Coral-seaweed-nutrient interaction on temperate reefs. Ecol Monogr 66:323-344

Miller MW, Weil E, Szmant AM (2000) Coral recruitment and juvenile mortality as structuring factors for reef benthic communities in Biscayne National Park, USA. Coral Reefs 19:115-123

Mumby PJ (2009) Herbivory versus corallivory: Are parrotfish good or bad for Caribbean coral reefs? Coral Reefs 28: 683-690

Mumby PJ, Harborne AR, Williams J, Kappel CV and others (2007) Trophic cascade facilitates coral recruitment in a marine reserve. Proc Natl Acad Sci USA 104:8362-8367

> Mundy CN (2000) An appraisal of methods used in coral recruitment studies. Coral Reefs 19:124-131

$>$ Neudecker S (1979) Effects of grazing and browsing fishes on the zonation of corals in Guam. Ecology 60:666-672

> Osman RW, Whitlatch RB (2004) The control of the development of a marine benthic community by predation on recruits. J Exp Mar Biol Ecol 311:117-145

- Ostfeld RS, Manson RH, Canham CD (1997) Effects of rodents on survival of tree seeds and seedlings invading old fields. Ecology 78:1531-1542

Penin L, Adjeroud M, Pratchett MS, Hughes TP (2007) Spatial distribution of juvenile and adult corals around Moorea (French Polynesia): implications for population regulation. Bull Mar Sci 80:379-389

Pratchett MS (2005) Dietary overlap among coral-feeding butterflyfishes (Chaetodontidae) at Lizard Island, northern Great Barrier Reef. Mar Biol 148:373-382

> Rotjan RD, Lewis SM (2005) Selective predation by parrotfishes on the reef coral Porites astreoides. Mar Ecol Prog Ser 305:193-201

Rotjan RD, Lewis SM (2008) Impact of coral predators on tropical reefs. Mar Ecol Prog Ser 367:73-91

Ruiz-Zarate MA, Arias-Gonzales JE (2004) Spatial study of juvenile corals in the northern region of the Mesoamerican Barrier Reef System (MBRS). Coral Reefs 23:584-594

Sammarco PW (1985) The Great Barrier Reef vs. the Caribbean: comparisons of grazers, coral recruitment patterns and reef recovery. Proc 5th Int Coral Reef Congr 4: 391-397

Sato M (1985) Mortality and growth of juvenile coral Pocillopora damicornis (Linnaeus). Coral Reefs 4:27-33

Smith LD, Hughes TP (1999) An experimental assessment of survival re-attachment and fecundity of coral fragments. J Exp Mar Biol Ecol 235:147-164

Steele MA, Forrester GE (2002) Early post-settlement predation on three reef fishes: effects of spatial patterns on recruitment. Ecology 83:1076-1091

> Stoner DS (1990) Recruitment of a tropical colonial ascidian: relative importance of pre-settlement vs. post-settlement processes. Ecology 71:1682-1690

Sundell J (2006) Experimental tests of the role of predation in the population dynamics of voles and lemmings. Mammal Rev 36:107-141

Tomascik T, vanWoesik R, Mah A (1996) Rapid coral colonisation of a recent lava flow following a volcanic eruption, Banda Islands, Indonesia. Coral Reefs 15:169-175

- Vermeij MJA (2006) Early life-history dynamics of Caribbean coral species on artificial substratum: the importance of competition, growth and variation in life-history strategy. Coral Reefs 25:59-71

Wilson J, Harrison P (2005) Post-settlement mortality and growth of newly settled reef corals in a subtropical environment. Coral Reefs 24:418-421

Wittenberg M, Hunte W (1992) Effects of eutrophication and sedimentation on juvenile corals. I. Abundance, mortality and community structure. Mar Biol 112:131-138 
Appendix 1. Estimation of bias introduced by the use of settlement tiles

To estimate eventual bias caused by the use of terracotta tiles in the sampling of recruits, we compared abundance and composition of recruits on 20 tiles deployed at each of the 9 study stations between September 2004 and December 2005 with abundance and composition of recruits on 20 pieces of natural substrata sampled in December 2005. Surface of pieces of natural substrata was estimated following Chancerelle (2000). Abundance $\left(\mathrm{m}^{-2}\right)$ of recruits on tiles at the 9 stations was strongly correlated with abundance of recruits on natural substrata (Pearson correlation, $\mathrm{R}=0.838, \mathrm{p}=0.0029$ ), even if abundance was higher on

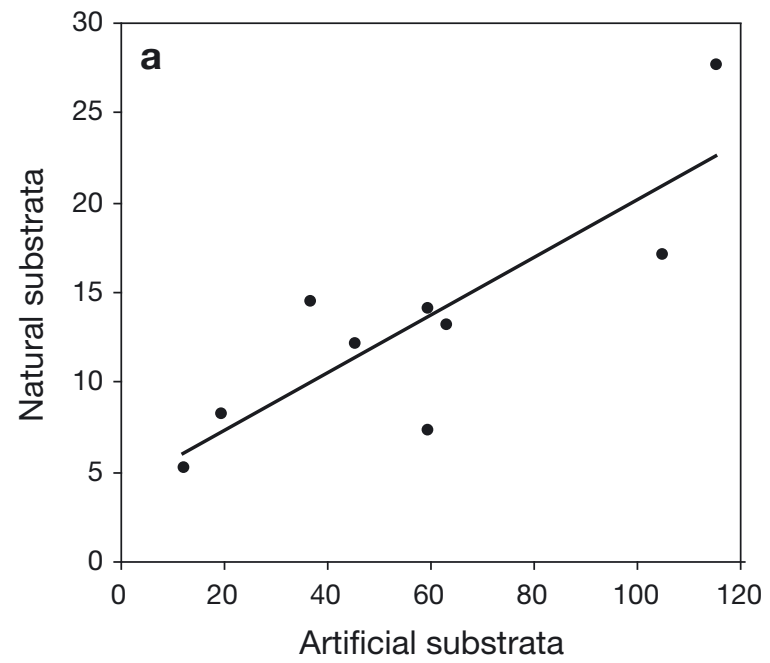

tiles than on natural substrata (Fig. A1a). Moreover, relative abundance of the families Acroporidae, Pocilloporidae and Poritidae did not significantly vary between natural and artificial substrata $\chi^{2}=0.9584, p=0.9609$ ) (Fig. A1b).

The present study aimed at comparing spatial variation of recruit abundance with spatial variations of juvenile and adult abundance. Since spatial patterns of variation and relative abundance of the studied taxa were consistent between artificial and natural substrata, we conclude that the use of terracotta tiles did not bias the results.

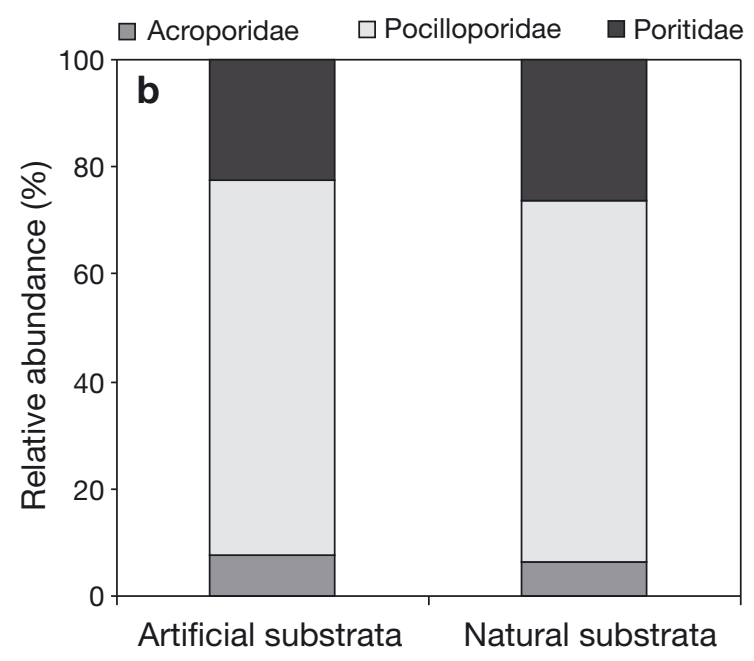

Fig. A1. (a) Mean recruit abundance $\left(\mathrm{m}^{-2}\right)$ on artificial (tiles) versus natural substrata at the 9 study stations. (b) Relative abundance of Acroporidae, Pocilloporidae and Poritidae on artificial (tiles) and natural substrata

Editorial responsibility: Peter Edmunds, Northridge, California, USA
Submitted: October 6, 2009; Accepted: February 23, 2010 Proofs received from author(s): May 31, 2010 